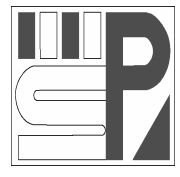

Science Press
Journal of Arid Land

2011, 3(4): 254-260

doi: 10.3724/SP.J.1227.2011.00254

jal.xjegi.com; www.chinasciencejournal.com

\title{
Altitudinal patterns of stand structure and herb layer diversity of Picea schrenkiana forests in the central Tianshan Mountains, Northwest China
}

\author{
LiPing $\mathrm{LI}^{1,2^{*}}$, XiangPing WANG ${ }^{3}$, Stefan ZERBE ${ }^{2}$, LiYun ZHANG ${ }^{4}$, JingYun FANG ${ }^{1}$ \\ ${ }^{1}$ Department of Ecology, College of Urban and Environmental Sciences \& Key Laboratory for Earth Surface Processes of the \\ Ministry of Education, Peking University, Beijing 100871, China; \\ ${ }^{2}$ Faculty of Science and Technology, Free University of Bolzano, Bolzano 39100, Italy; \\ ${ }^{3}$ The Key Laboratory of Silviculture and Conservation of the Ministry of Education, College of Forestry, Beijing Forestry Uni- \\ versity, Beijing 100083, China; \\ ${ }^{4}$ Xinjiang Institute of Ecology and Geography, Chinese Academy of Sciences, Urumqi 830011, China
}

\begin{abstract}
Altitude is a useful indicator to examine patterns of forest structure and species diversity in relation to environmental factors. In this study, the altitude patterns of forest stand structure and species diversity were analyzed across 20 plots in the Tianchi Nature Reserve, Northwest China. The results showed that mean stem height $\left(H_{m}\right)$, maximum stem height $\left(H_{m a x}\right)$ and mean stem diameter at breast height $\left(D_{m}\right)$ of Picea schrenkiana trees all decreased significantly with increasing altitude. Potential tree height $\left(\mathrm{H}^{*}\right)$ decreased while stem taper increased significantly as altitude increased, suggesting remarkable altitudinal changes in biomass allocation between the diameter and height growth of Picea schrenkiana. Understory herbaceous richness increased significantly with increasing altitude, or with decreasing total basal area (TBA), $\mathrm{H}_{\mathrm{m}}$ and stand volume (Volume). High light availability for understory herbs might account for the higher species richness at high altitude. Sorensen Index decreased significantly with the increase in altitude intervals, while the Cody Index demonstrated a converse pattern, suggesting greater differences in species composition with larger distances.
\end{abstract}

Keywords: allometry; beta diversity; species richness; Picea schrenkiana; Tianshan Mountains; Xinjiang

Forest stand structure and plant diversity are closely related to environmental factors (Aiba and Kitayama, 1999). These relations are not only evident on large scales but also observed at local scales, e.g. within the same forest type (Zheng et al., 2004a). The altitudinal gradient are highly correlated with energy and water (He and Chen, 1997), which provides a useful tool to examine the mechanisms underlying the variations in forest structure and plant diversity with environmental factors (Fang et al., 2004a).

Diameter and height growth are two important aspects of tree growth. The diameter growth is related to tree support, water absorption and leaf biomass, while the height growth is related to light interception. The relationship between diameter at breast height and stem height $(\mathrm{DBH}-\mathrm{H})$ reflects the trade-off between stem diameter and height growth (Aiba and Kohyama, 1996). DBH-H is closely related to environmental factors, such as climate and soil fertility, and thus is expected to change with altitude (Aiba and Kitayama, 1999).

Recent researches by Li et al. (2011a, b and c) revealed significant latitudinal and longitudinal patterns of forest structure, species diversity and $\mathrm{DBH}-\mathrm{H}$ allometry in Xinjiang mountains. However, the altitudinal patterns of all these traits have seldom been systematically examined in these areas. Xinjiang is the most arid region in China (Forestry Administration of

Received 2011-04-13; accepted 2011-07-01

*Corresponding author: LiPing LI (E-mail: liliping@pku.edu.cn) 
China, 1989), and thus we predicted that the altitudinal patterns would show obvious differences from studies in the humid regions of China (e.g. Zheng et al., 2004a and b; Zhu et al., 2004), but indicates similar trends as the latitudinal/longitudinal patterns demonstrated in the same region (Li et al., 2011a, b and c).

In this study, the Picea schrenkiana forests in the Tianshan Mountains were used as an example to examine the altitudinal patterns of forest structure and diversity in the arid region. P. schrenkiana has been a relict species since the Tertiary period and is endemic to the mountains of Central Asia. P. schrenkiana forests account for the largest proportion of area and stand volume in Xinjiang's forests and play an important role in soil and water conservation in the Tianshan Mountains (Wang and Zhao, 1999). The Tianchi Nature Reserve is designed to protect the natural $P$. schrenkiana forests located in the central Tianshan Mountains, and thus provides an ideal site for this study.

We analyzed an altitudinal gradient within $P$. schrenkiana forests, focusing on the following two questions: (1) How do the stand parameters, such as stem diameter and height growth of $P$. schrenkiana trees change along the altitudinal gradient? (2) How do the species composition and plant diversity in the $P$. schrenkiana forests change along the altitudinal gradient?

\section{Study area and methods}

\subsection{Study area}

The Tianchi Nature Reserve $\left(88.00-88.33^{\circ} \mathrm{E}, 43.75-\right.$ $43.98^{\circ} \mathrm{N}$ ) is located in the upper region of the Sangong River, Fukang city in the central Tianshan Mountains in Xinjiang Uygur autonomous region, Northwest China. The annual precipitation in this region is about $400-500 \mathrm{~mm}$ and the mean annual temperature is about $0-4^{\circ} \mathrm{C}$. The major soil type is mountain grey-brown forest soil according to the Chinese soil classification system (Forestry Administration of China, 1989; Wang et al., 2004).

Along the altitudinal gradient from the valley to the mountain tops on the northern slope of the Tianshan Mountains, the landscape changes from mountain steppes to mountain forests to alpine grasslands and to mountain snow and glacier belts (Xinjiang Integrated Survey Team, Institute of Botany, Chinese Academy of Sciences, 1978). P. schrenkiana forests occur from $1,250-1,600 \mathrm{~m}$ to $2,700-2,800 \mathrm{~m}$ a.s.l. and are mainly distributed along the northern slopes, which have high water availability (Forestry Administration of China, 1989). Tourism and summer grazing are the main human activities in this region. We focus on the forests above the Tianchi Lake (1,980 $\mathrm{m}$ a.s.1.) where there is relatively less human impact.

\subsection{Sampling of vegetation and stand structure}

The plots were set along the gradient, from 2,100 $\mathrm{m}$ to $2,700 \mathrm{~m}$ a.s.1., with the altitude interval of $80 \mathrm{~m}$, and two replicates at each altitude. According to the method of Braun-Blanquet (1964), the plots were chosen in homogenous forest stands with limited human activities (Fig. 1). In total, 20 plots were sampled with an area of $20 \mathrm{~m} \times 30 \mathrm{~m}$ each. In each plot, all tree, shrub, and herb species were recorded. DBH $(\geq 3 \mathrm{~cm})$ and the heights of trees were measured with tape measure and hypsometer (Fang et al., 2004b). The geographical range of the plots was $88.09-88.12^{\circ} \mathrm{E}$ and $43.88-43.91^{\circ} \mathrm{N}$ (Fig. 1). The altitudes were recorded by pressure altimeter. The field work was done in August of 2006.

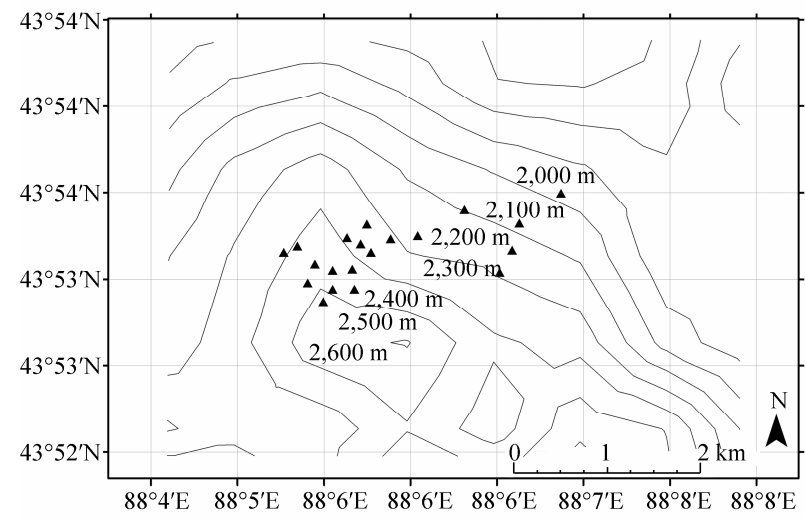

Fig. 1 The sampling sites of study area (the contour line is from DEM data of USGS with a resolution of $1 \mathrm{~km} \times 1 \mathrm{~km}$. The altitudes of the plots $(\mathbf{\Lambda})$ were recorded by pressure altimeter.

\subsection{Data analysis}

\subsubsection{Relationship between forest stand structure and} DBH-H

Seven indices were selected as the indicators for forest stand structure, i.e. mean $\mathrm{DBH}\left(\mathrm{D}_{\mathrm{m}}, \mathrm{cm}\right)$, maximum DBH $\left(D_{\max }, c m\right)$, mean stem height $\left(H_{m}, m\right)$, maximum stem height $\left(\mathrm{H}_{\max }, \mathrm{m}\right)$, total basal area (TBA, $\mathrm{m}^{2} / \mathrm{hm}^{2}$ ), stand volume (Volume, $\mathrm{m}^{3} / \mathrm{hm}^{2}$ ) and stem density (Density, stem $/ \mathrm{hm}^{2}$ ). The volume was calcu- 
lated according to the volume tables from the Forestry Administration of China (1978).

The DBH-H relationship was revealed by a generalized allometric model denoted in Eq. (1) following Ogawa (1969) and a simple allometric model denoted in Eq. (2).

$$
\begin{aligned}
& \frac{1}{H}=\frac{1}{a D^{b}}+\frac{1}{H^{*}}, \\
& H=a \times D^{b} .
\end{aligned}
$$

Where, $H$ represents stem height, and $D$ represents diameter at breast height, while $a, b$ and $H^{*}$ are regression coefficients. $H^{*}$ indicates the potential tree height, i.e. the upper limit of the stem height in the local environment, if there are significant differences between Eqs. (1) and (2) (Aiba and Kohyama, 1997). As a result, $H^{*}$ values are not used in data analyses if the differences between Eq. (1) and Eq. (2) are not significant.

The Taper was calculated as an indicator for the resource allocation in height and diameter growth of trees (Eq. (3); Paatalo et al., 1999). More resources are allocated to diameter growth with higher Taper value, and vice versa.
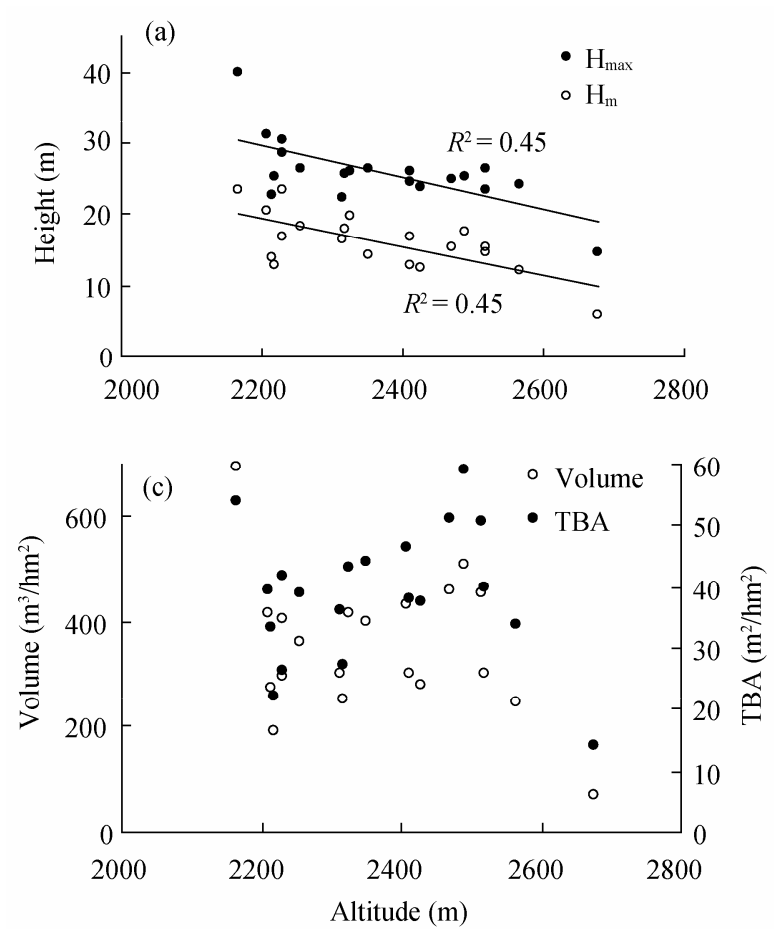

$$
\text { Taper }=D_{m} / H_{m}
$$

Where, $D_{m}$ and $H_{m}$ represent the mean diameter at breast height $(\mathrm{cm})$ and mean stem height $(\mathrm{m})$ of all stems in the plots, respectively.

\subsubsection{Species diversity}

The Sorensen Index shown in Eq. (4) and Cody Index shown in Eq. (5) were used to measure the similarity and dissimilarity in plant composition among different plots (Whittaker, 1972; Magurran, 1988).

$$
\begin{aligned}
& \text { Sorensen Index: } S I=\frac{2 c}{a+b}, \\
& \text { Cody Index: } \beta_{c}=\frac{a+b-2 c}{2} .
\end{aligned}
$$

Where, $a$ and $b$ are the number of species that appear only in plot 1 or plot 2, respectively; $c$ is the number of species that appears in both plot 1 and plot 2 .

According to Aiba and Kitayama (1999), we defined species that appear only in plots at one altitude as the Restricted Species (RS) of the altitude. The Restricted Species Ratio (RS\%) was calculated by dividing the number of RS by total species richness at the same altitude.
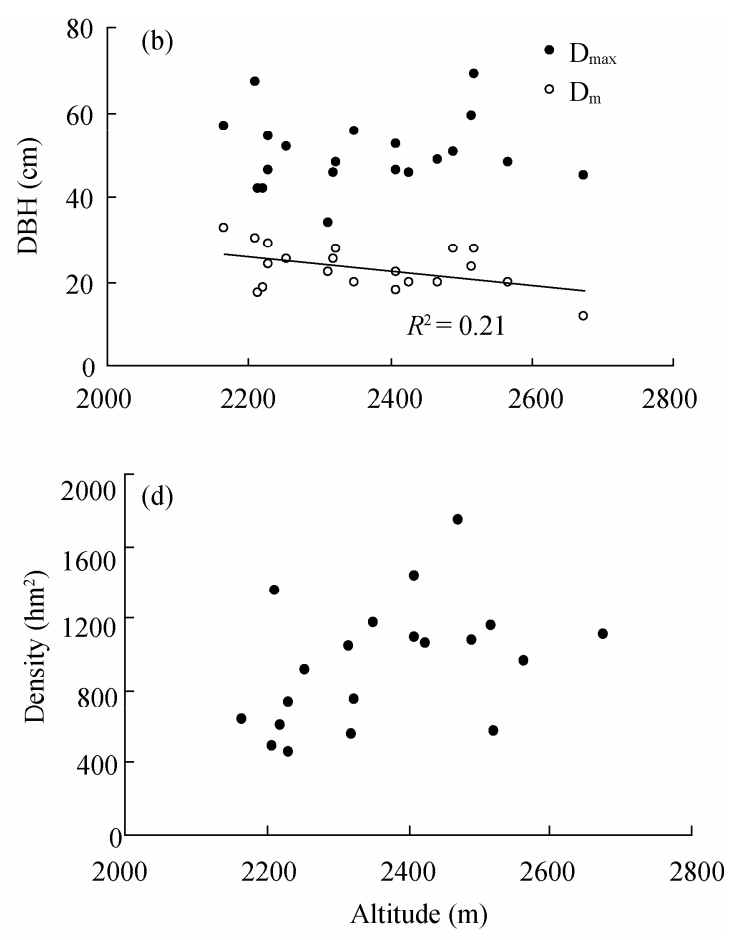

Fig. 2 Changes in the stand structure with altitude in $P$. schrenkiana forests of the Tianchi Nature Reserve, Xinjiang (a, $H_{m} \& H_{m a x} ; b, D_{m}$ $\& D_{\max } ; c$, Volume \& TBA and $d$, Density) 


\section{Results and discussion}

\subsection{Relationship between forest stand structure and DBH-H}

The average density of $P$. schrenkiana forests is 944 stems $/ \mathrm{hm}^{2}$ with averaged DBH $23.1 \mathrm{~cm}, \mathrm{H} 16.1 \mathrm{~m}$, TBA $38.8 \mathrm{~m}^{2} / \mathrm{hm}^{2}$ and Volume $352.7 \mathrm{~m}^{3} / \mathrm{hm}^{2}$. There are different relationships between stand structure parameters and altitudes. $\mathrm{H}_{\max }\left(R^{2}=0.45, P<0.05\right), \mathrm{H}_{\mathrm{m}}$ $\left(R^{2}=0.45, P<0.05\right)$ and $\mathrm{D}_{\mathrm{m}}\left(R^{2}=0.21, P<0.05\right)$ decreased with increasing altitude, while $\mathrm{D}_{\max }$, Volume, TBA and Density did not change significantly (Fig. $2 \mathrm{a}-\mathrm{d})$. The results indicate that the growth of stem height is more sensitive to the change in altitude than that of stem diameter in this region $\left(R^{2}=0.45\right.$ and 0.21 for $\mathrm{H}_{\mathrm{m}}$ and $\mathrm{D}_{\mathrm{m}}$ against altitude, respectively). Li et al. (2011a) found that stem height growth was more influenced by annual precipitation while the growth of stem diameter was more influenced by mean annual temperature in the coniferous forests of Xinjiang. In the Tianchi Nature Reserve, the altitudinal gradient mainly represents the gradient of water availability. Therefore, the altitudinal patterns shown here are consistent with those revealed results along the latitudinal gradients, suggesting similar responsive mechanism of stem diameter and height growth to climate factors.

$H^{*}$ (a potential tree height) is an indicator of the site condition. The maximum tree height can be used to evaluate the productivity of forests (Ryan, 1997; Fang et al., 2006). In our study areas, the average $H^{*}$ is $27.3 \mathrm{~m}$ and the max $H^{*}$ is $39.7 \mathrm{~m}$. $H^{*}$ decreased significantly with increasing altitude $\left(R^{2}=0.48 ; P<0.05\right)$ (Fig. 3b), which reflects that forest environmental conditions at low altitude are better than at high alti- tude. This result is consistent with that of Li et al. (2011c) for the whole coniferous forests among the mountains in Xinjiang.

The Taper represents the allometric relationship of DBH-H. In this region, the Taper is $1.47 \mathrm{~cm} / \mathrm{m}$, which is lower than the averaged value of the coniferous forests as a whole in Xinjiang (Taper $=1.69 \mathrm{~cm} / \mathrm{m} ; \mathrm{Li}$ et al., 2011c). The Taper increased with increasing altitude $\left(R^{2}=0.52 ; P<0.05\right)$ (Fig. 3a), i.e. more biomass is allocated to the diameter growth at higher altitude. Wang et al. (2006) found that severe winter in the northeast region of China may lead to more diameter growth compared to height growth. These results indicated that more biomass is allocated to stem diameter growth in harsh climatic conditions and site conditions (e.g., at high altitude).

\subsection{Herb species diversity}

2.2.1 Relationships between herb species diversity and altitude and stand structures

The species composition of $P$. schrenkiana forests is simple; $P$. schrenkiana is the dominant tree species with Salix caprea and Sorbus tianschanica sporadically distributed in the tree layer. As for the shrub layer, only Lonicera heterophylla, Juniperus pseudosabina, Rosa acicularis, Spiraea chamaedryfolia and Berberis hetropoda are presented with low cover. The whole diversity of $P$. schrenkiana forests is rich in herb layer. The herb diversity of $P$. schrenkiana forests was analyzed as a substitute for the forest diversity. There are 88 herb species ( 73 genus and 33 families) recorded in 20 plots of the P. schrenkiana forests. Compositae (10 species), Gramineae (8 species), Rosaceae (6 species) and Caryophyllaceae (6 species) are the main families in this region. There is an aver-
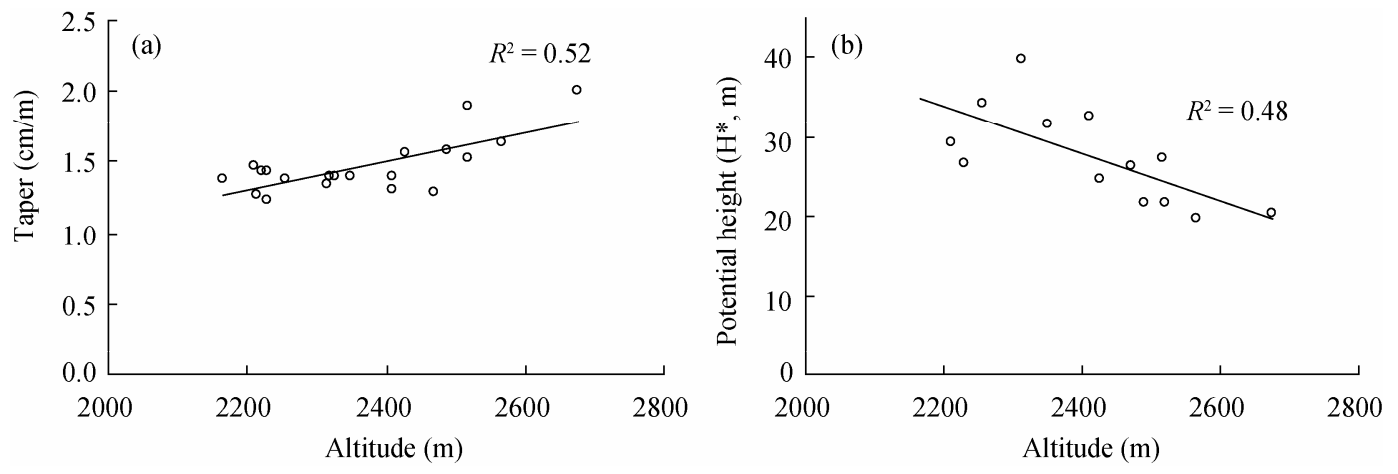

Fig. 3 Changes in the Taper (a) and $\mathrm{H}^{*}$ (b) with the altitude in $P$. schrenkiana forests of the Tianchi Nature Reserve, Xinjiang 
age of 19 species per plot. There are species, such as Swertia marginata and Potentilla multifida distributed only at high altitude where there are special high altitude timberline habitats. There are also some species distributed only at low altitude where human disturbances are frequent, such as Plantago depressa.

Herb species richness increases with an increase in altitude $\left(R^{2}=0.45 ; P<0.05\right)$; and decreased with an increase in $\mathrm{H}_{\mathrm{m}}$, TBA and Volume $\left(R^{2}=0.30,0.38,0.55\right.$; $P<0.05)$; yet it did not change significantly with increasing $\mathrm{D}_{\mathrm{m}}$ and Density $\left(R^{2}=0.02,0.11 ; P>0.05\right)$ (Fig. $4 \mathrm{a}-\mathrm{f})$. Herb species richness is more influenced by stem height than by stem diameter, suggesting that the growth of herbs is more controlled by light availability.
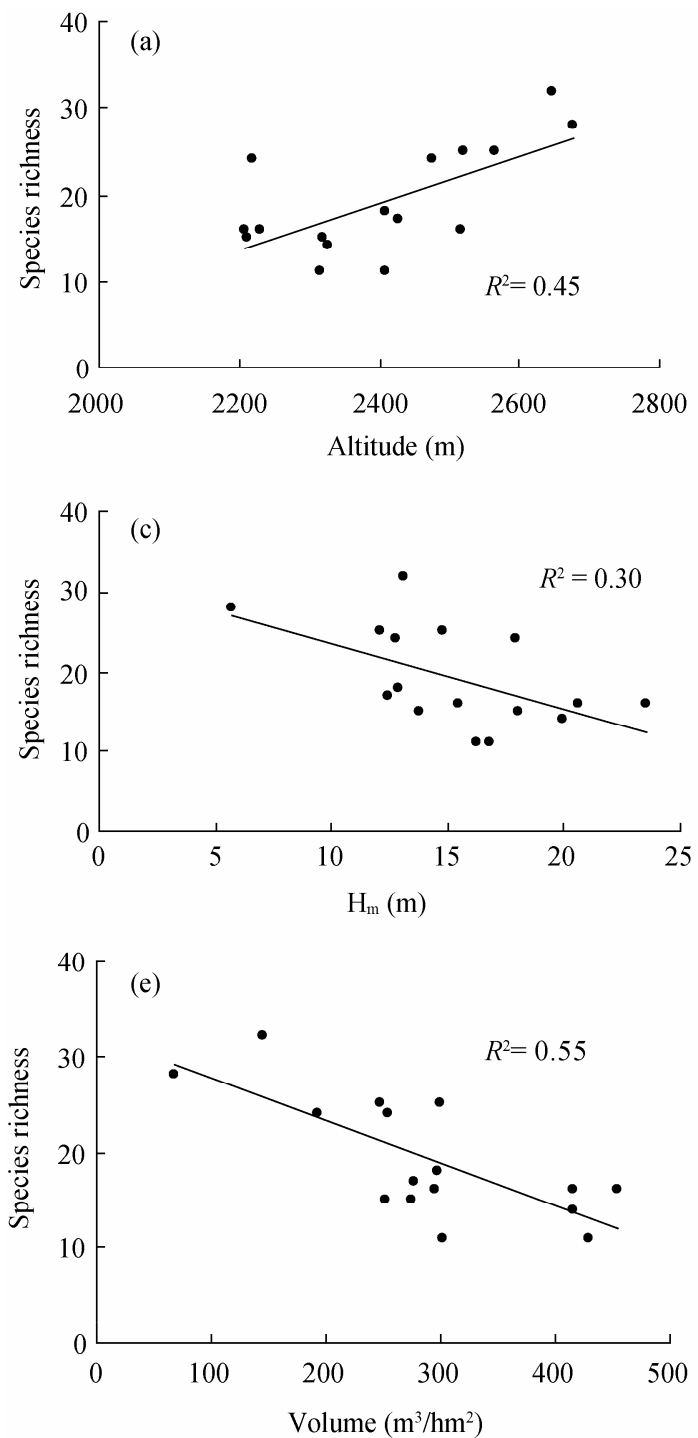

More herb species are distributed at high altitude probably because stem heights are lower than at low altitude, which means more light available for herb layer at high altitude. Pyrcz et al. (2009) found that the richness and abundance of Pronophilina butterflies increased as altitude increased. The higher speciation ratio towards high elevations, particularly near timberline, help form this pattern. Species richness also had a decrease (Tang et al., 2004; Li et al., 2011b) or humped pattern (Zheng et al., 2004b; Zhu et al., 2004) with the increase of altitude. The intrinsic reason for these patterns is more important than the pattern itself. In this region, more species are distributed at high altitude because of the specific habitat and high light
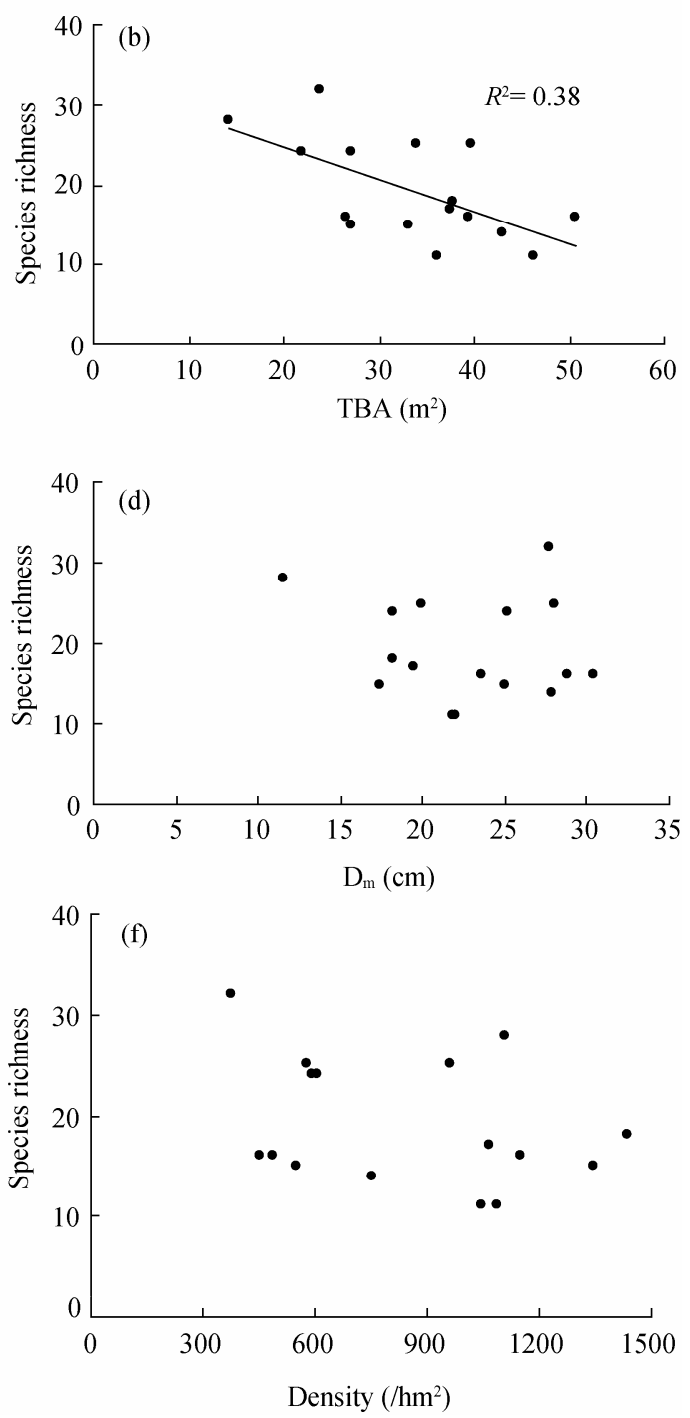

Fig. 4 Changes in the species richness of herbs with altitude (a) and stand structure (b) TBA; (c) $H_{m}$; (d) $D_{m}$; (e) Volume and (f) Density in P. schrenkiana forests of the Tianchi Nature Reserve, Xinjiang 

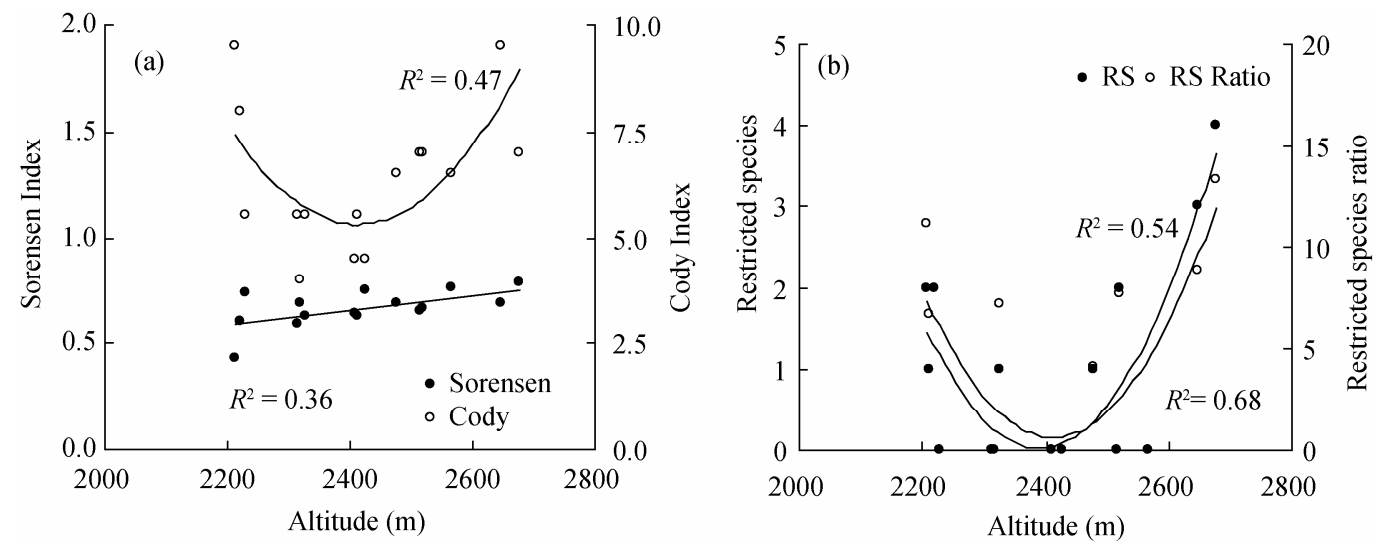

Fig. 5 Changes in the Sorensen Index and Cody Index of herbs (a), Restricted species (RS) and Restricted species ratio (RS Ratio) of herbs (b) with altitudes in P. schrenkiana forests of the Tianchi Nature Reserve, Xinjiang

availability, while human disturbances result in lower species richness at low altitude.

2.2.2 The relationship between plant species composition and altitude

The Sorensen Index indicates the similarity of species composition. The Sorensen Index increases with increasing altitude $\left(R^{2}=0.36, P<0.05\right)$ (Fig. 5a). The specific habitat is the reason why species composition is similar at high altitudes. The Cody Index shows an inverse-humped pattern as altitude increased $\left(R^{2}=0.47\right.$, $P<0.05$ ) (Fig. 5a), as do the Restricted species and Restricted species ratio (Fig. 5b). The results indicate that the number of species at middle altitudes are the mixture within the high to low altitudes, or the species at the middle altitudes more easily spread to low and high altitudes, which make species composition at the middle altitude similar to those at both high and low altitudes. Tang and Ke (2004) also found similar patterns of the Cody Index in the Qinling Mountains of China, where vegetation transition at high altitudes and human disturbances at low altitudes resulted in this pattern. In the Tianchi Nature Reserve, human disturbances at low altitude and specific timberline habitat at high altitude are the potential reason for this inverse-humped pattern.

Figure 6 indicates changing patterns of the Sorensen Index and the Cody Index for all intervals of altitude. The Sorensen Index decreased as altitude intervals increase $\left(R^{2}=0.12, P<0.05\right)$, while the Cody Index increases significantly as altitude intervals increase $\left(R^{2}=0.32, P<0.05\right)$. This shows that the distance affected the plant species composition along the altitud- inal gradients. Species compositions are more similar to each other at altitudes with closer distances, vice versa.

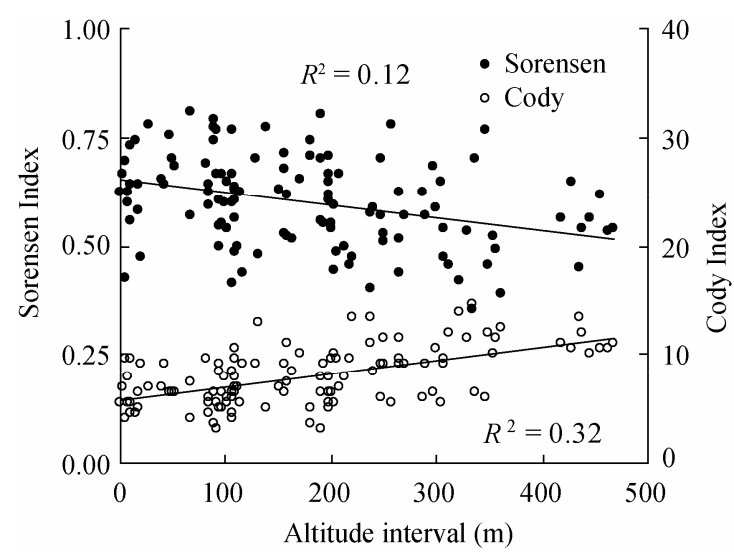

Fig. 6 Changes in the Sorensen Index and Cody Index of herbs with altitude intervals in $P$. schrenkiana forests of the Tianchi Nature Reserve, Xinjiang

\section{Conclusion}

Among the seven structure parameters, the stem height had the closest relationship with altitude in Picea schrenkiana forests, decreasing significantly with increasing altitude. The stem density and mean diameter at breast height had relatively weak relationships with altitude. The potential height of $P$. schrenkiana forests decreased while the Taper increased significantly with increasing altitude, suggesting that height growth is relatively slower than diameter growth at high altitude due to the harsh environment of habitat.

A total of 10 woody species and 88 herb species were recorded in 20 plots. Herb species richness increased significantly as altitude increased, while decreased significantly with increases of TBA, $H_{m}$ and 
Volume. Plant species compositions were more similar at high than at middle and low altitudes. The similarity of plant species composition decreased significantly as distance increased.

\section{Acknowledgements}

This research is supported by the National Basic Research Program of China (2010CB950602). We thank ZhengLei XIE and YiNing LIU of Peking University,

\section{References}

Aiba S-I, Kohyama T. 1996. Tree species stratification in relation to allometry and demography in a warm-temperate rain forest. Journal of Ecology, 84(2): 207-218.

Aiba S-I, Kohyama T. 1997. Crown architecture and life-history traits of 14 tree species in a warm-temperate rain forest: significance of spatial heterogeneity. Journal of Ecology, 85(5): 611-624.

Aiba S-I, Kitayama K. 1999. Structure, composition and species diversity in an altitude-substrate matrix of rain forest tree communities on Mount Kinabalu, Borneo. Plant Ecology, 140(2): 139-157.

Braun-Blanquet J. 1964. Plant Sociology: the Study of Plant Communities, $3^{\text {rd }}$ ed. Vienna: Springer.

Fang J Y, Shen Z H, Cui H T. 2004a. Ecological characteristics of mountains and research issues of mountain ecology. Biodiversity Science, 12(1): 10-19.

Fang J Y, Shen Z H, Tang Z Y, et al. 2004b. The protocol for the survey plan for plant species diversity of China's mountains. Biodiversity Science, 12(1): 5-9.

Fang J Y, Brown S, Tang Y H, et al. 2006. Overestimated biomass carbon pools of the northern mid- and high latitude forests. Climatic Change, 74: 355-368.

Forestry Administration of China. 1978. Tree Volume Tables (National Standard) (LY 208-77). Beijing: Technology Standard Press.

Forestry Administration of China. 1989. Xinjiang Forest. Beijing: China Forestry Press.

He J S, Chen W L. 1997. A review of gradient changes in species diversity of land plant communities. Acta Ecologica Sinica, 17(1): 91-99.

Li L P, Liu Y N, Tang Z Y, et al. 2011a. Community structure and its affecting factors of mountain coniferous forests in Xinjiang, China. Arid Zone Research, 28(1): 31-39.

Li L P, Mohammat A, Guo Z D, et al. 2011b. Study on plant species composition and richness of the mountain coniferous forests in Xinjiang. Arid Zone Research, 28(1): 40-46.

Li L P, Mohammat A, Wang X P. 2011c. Study on relationship between height and DBH of mountain coniferous forests in Xinjiang. Arid Zone Research, 28(1): 47-53.

Magurran A E. 1988. Ecological Diversity and its Measurement. Princeton, New Jersey: Princeton University Press.

Ogawa H. 1969. An attempt at classifying forest types based on the relationship between tree height and DBH. In: Kira T. Comparative Study of Primary Productivity in Forest Ecosystems. JIBP-PT-F Progress Reports for 1968: 3-17.
Chao CAI and FengLiang ZHU of Xinjiang Agricultural University and Anwar MOHAMMAT of the Xinjiang Institute of Ecology and Geography, Chinese Academy of Sciences for their generous help in the field work. We also thank ZhiYao TANG, WenXuan HAN and ZhiHeng WANG of Peking University, Elizabeth GEORGE of the Free University of Bolzano and the anonymous reviewers for their suggestions to the manuscript.

Paatalo M-L, Peltola H, Kellomaki S. 1999. Modeling the risk of snow damage to forests under short-term snow loading. Forest Ecology and Management, 116: 51-70.

Pyrcz T W, Wojtusiak J, Garlacz R. 2009. Diversity and distribution patterns of Pronophilina butterflies (Lepidoptera: Nymphalidae: Satyrinae) along an altitudinal transect in north-western Ecuador. Neotropical Entomology, 38(6): 1-11.

Ryan M G, Yoder B J. 1997. Hydraulic limits to tree height and tree growth. Bioscience, 47(4): 235-242.

Tang Z Y, Fang J Y, Zhang L. 2004. Patterns of woody plant species diversity along environmental gradients on Mt. Taibai, Qinling Mountains. Biodiversity Science, 12(1): 115-122.

Tang Z Y, Ke J H. 2004. Altitudinal patterns of plant species diversity in Mt. Niubeiliang, Qinling Mountains. Biodiversity Science, 12(1): 108-114.

Wang T, Liang Y, Ren H B, et al. 2004. Age structure of Picea schrenkiana forest along an altitudinal gradient in the central Tianshan Mountains, northwestern China. Forest Ecology and Management, 196: 267-274.

Wang X P, Fang J Y, Tang Z Y, et al. 2006. Climatic control of primary forest structure and DBH-height allometry in Northeast China. Forest Ecology and Management, 234: 264-274.

Wang Y, Zhao S D. 1999. Biomass and net productivity of Picea schrenkiana var. tianshanica forest. Chinese Journal of Applied Ecology, 10 (4): 389-391.

Whittaker R H. 1972. Evolution of measurement of species diversity. Taxon, 21: 213-251.

Xinjiang Integrated Survey Team, Institute of Botany, Chinese Academy of Sciences. 1978. The Vegetation and its Utilization in Xinjiang. Beijing: Science Press.

Zheng C Y, Fang J Y, He J Y. 2004a. Effects of topographical factors on distribution of Phyllostachys pubescens in Wuyishan Nature Reserve, Fujian province, China. Biodiversity Science, 12(1): 75-81.

Zheng C Y, Liu Z L, Fang J Y. 2004b. Tree species diversity along altitudinal gradient on southeastern and northwestern slopes of Mt. Huanggang, Wuyi Mountains, Fujian, China. Biodiversity Science, 12 (1): 63-74.

Zhu B, Chen A P, Liu Z L, et al. 2004. Changes in floristic composition, community structure, and tree species diversity of plant communities along altitudinal gradients on Mt. Mao'er, Guangxi, China. Biodiversity Science, 12(1): 44-52. 